\title{
Mental disturbances after thalamolysis
}

\author{
E. S. WATKINS AND D. R. OPPENHEIMER \\ From the Departments of Neurological Surgery and Neuropathology, \\ Radcliffe Infirmary, Oxford
}

This report concerns two patients, in both of whom the placing of a lesion in the left thalamus, for the purpose of controlling Parkinsonian tremor and rigidity, resulted in a severe and protracted psychic disturbance, characterized by confusion, amnesia, confabulation, and euphoria. One of these patients died, from other causes, nine months after operation. A detailed anatomical and histological examination was carried out on the brain, primarily in order to define the nature and extent of the lesion produced by the balloon-and-cannula technique (Cooper, 1959).

CASE 1 (R.I. No. 94194) The patient was a 57-year-old, normotensive, right-handed man. Over the past 18 years he had gradually developed a severe, and ultimately disabling, tremor of the right hand and arm. More recently, he had suffered from excessive salivation and slowing of gait and of speech. At the time of admission, he was unable to use the right hand for eating, dressing, shaving, or writing. All limbs showed moderate 'cogwheel' rigidity and there was tremor of the right leg and left arm. He was judged to be of average intelligence, and showed no sign of recent mental impairment or dysphasia. He was said to be naturally shy and retiring, and had been in low spirits for the past year or two. His disability had lost him his job a few months before admission.

A left thalamolysis, using Cooper's (1959) technique, was undertaken. The first part of the operation (ventriculography and placing of the Cooper cannula in the ventrolateral nuclear mass of the thalamus under radiological control, see Fig. 3h) was without incident. When the balloon was inflated with $0.5 \mathrm{ml}$. of Myodil, the patient instantly shouted 'Stand by, everyone in the aircraft' and from that moment was hallucinated, irrational, and inaccessible. At first he was excited, and tried to get down from the operating table in order, as he said, to visit the income tax inspector; later he became drowsy.

Over the next few days he became more accessible, but was doubly incontinent and utterly confused as to time and place. At times he failed to recognize his wife and relations, and would deny that he was married. When asked where he was, he gave varied answers: that he was at the factory where he worked, or that he was at the Liverpool Cotton Exchange, where he had worked previously. He fairly consistently gave the date as some time in the 1920s, and his age as 27. Meanwhile, the tremor of the right upper limb had practically disappeared, and showed itself only when the patient was excited. There was no weakness of the right side as compared with the left, but the right plantar reflex was extensor.

On the day after operation skull radiographs showed that the balloon had leaked, and that Myodil was lying free near the site of the lesion. Because of the patient's mental state, it was not till the fourth post-operative day that $0.25 \mathrm{ml}$. of Etopalin $(8 \%$ methyl cellulose, $15 \%$ Pantopaque, in $90 \%$ ethyl alcohol) was injected through the cannula. Shortly after this, the patient again became inaccessible and uncontrollably restless and destructive. He tended to wander about the ward naked, played with excrement, and had to be sedated with paraldehyde. Three days later, he had become quieter and more amenable, and a further $0.25 \mathrm{ml}$. of Etopalin was injected. A radiograph taken at this time showed an irregularly-shaped injection mass (Figs. 1 and 2), and indicated some reflux of the material along the track of the cannula. As before, the injection rendered the patient unmanageable, and it was considered that treatment had been carried far enough.

Over the next few days, the patient's mental state began to improve. As communication became easier, it became clear that he now had a well-marked nominal dysphasia and gross amnesia for recent events. His mood was mainly euphoric and expansive. Three weeks after operation, he was alert, continent and fairly cooperative, but still confused and amnesic, with a definite nominal dysphasia but no receptive defect. There was no weakness of the right limbs or any detectable sensory loss. The functional improvement in the right upper limb was maintained, and the patient could now use a knife and fork, manipulate buttons, and strike matches satisfactorily. He was discharged home at this stage.

For the next three or four weeks, the dominant mood was one of jocular expansiveness. After that, as insight and memory returned, and confusion cleared up, the patient became increasingly depressed. Nine weeks after operation, he was fully orientated and no longer dysphasic but anxious and miserable. Memory was intact up to the episode of inflating the balloon, but the next three weeks were a complete blank. Psychometric tests performed six months after operation showed a good average intelligence, with no memory deficit. During the testing, he was observed to be anxious and suspicious. Some of the anxiety concerned his application to return to his old job, over which there were negotiations lasting several months. During this period he was often extremely depressed, and talked of having 'wicked thoughts'-- 


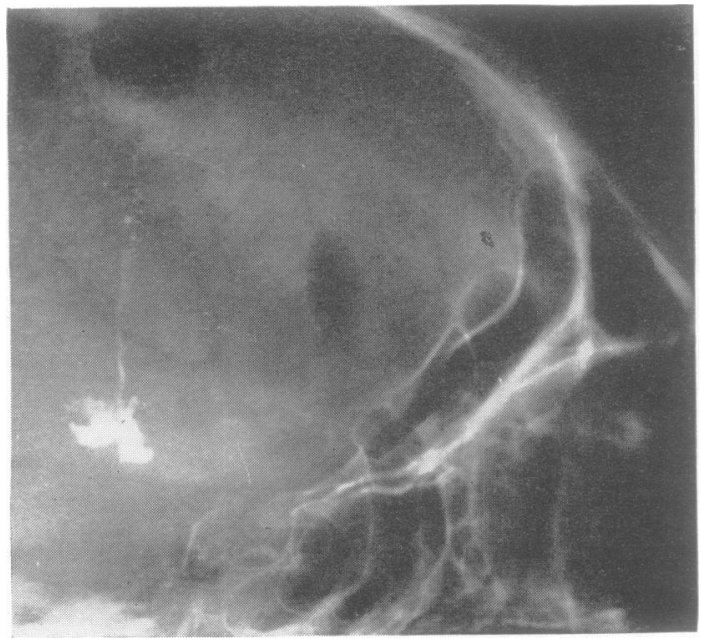

FIG. 1

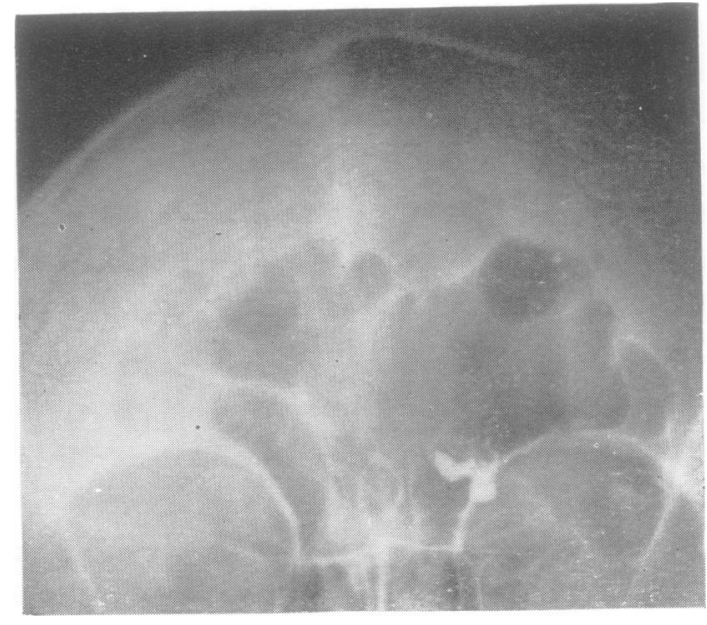

FIG. 2

FIGS. 1 and 2. Case 1: lateral and antero-posterior radiographs, showing injection mass one week after operation. Note the spread of Myodil along the cannula track.

presumably suicidal. In fact, he committed suicide by carbon monoxide poisoning nine months after the operation.

\section{NECROPSY FINDINGS}

The brain was made available by the kindness of Dr. H. D. Leggatt, who performed the necropsy for H.M. coroner. It was of normal size, and looked normal externally apart from a scar $1 \mathrm{~cm}$. in diameter in the cortex of the left middle frontal gyrus, approximately $6 \mathrm{~cm}$. behind the frontal pole. There were only slight atheromatous changes in the arteries at the base.

After fixation, the cerebrum was sliced coronally at $4 \mathrm{~mm}$. intervals. The slices showed the extent of the surgical lesion, which is described below. The only other naked-eye feature was a generalized shrinkage of the left thalamus as compared with the right. In the brain-stem there was obvious loss of pigment in the substantia nigra and locus pigmentosus pontis on both sides. This was most marked in the left substantia nigra. Otherwise, the brain-stem and cerebellum appeared normal.

\section{HISTOLOGY}

Characteristic lesions of paralysis agitans were seen in the substantia nigra and locus pigmentosus pontis of both sides. There was a severe loss of pigmented cells in the substantia nigra, with gliosis; the medially-placed cells on the right were relatively spared. Lewy inclusion bodies were seen in all four situations, and in the reticular formation in the medulla. Minor degenerative changes, such as are commonly found in elderly brains, were seen in the putamen and globus pallidus on both sides.

The extent of the surgical lesion is shown in Fig. 3a to g, and Fig. 4. The track of the cannula began in the left middle frontal gyrus at a level just in front of the anterior commissure, and passed downwards, backwards, and medially through the anterior limb and genu of the internal capsule to the ventrolateral nuclear mass of the thalamus (Figs. 3a to $\mathrm{d}$, and $3 \mathrm{~g}$ ). The main lesion extended downwards and forwards from this point, involving the internal capsule (Fig. 3c) and the medial tip of the globus pallidus, approaching closely to the optic tract (Fig. 3b). There was a backward extension (Figs. 3d to f) lying well inside the ventrolateral mass of the thalamus. The dimensions of the main lesion were: $20 \mathrm{~mm}$. from before back, $12 \mathrm{~mm}$. from above down, and $6 \mathrm{~mm}$. from side to side (cf. Figs. $3 \mathrm{~g}$ and $h$ ).

Microscopically, the lesion consisted of a central core of necrotic débris, surrounded by a fibrous capsule 1 to $2 \mathrm{~mm}$. thick. The inner surface of the capsule contained numerous multinucleate foreignbody giant cells, while on the outer surface there were irregular accumulations of chronic inflammatory cells, lymphocytes, plasma cells, macrophages, and occasional eosinophils. Scattered among these cells were small masses of a golden-brown material (presumably Myodil), some of which was intracellular. Beyond was a zone of necrosis up to $2 \mathrm{~mm}$. in extent, traversed by vascular strands and con- 

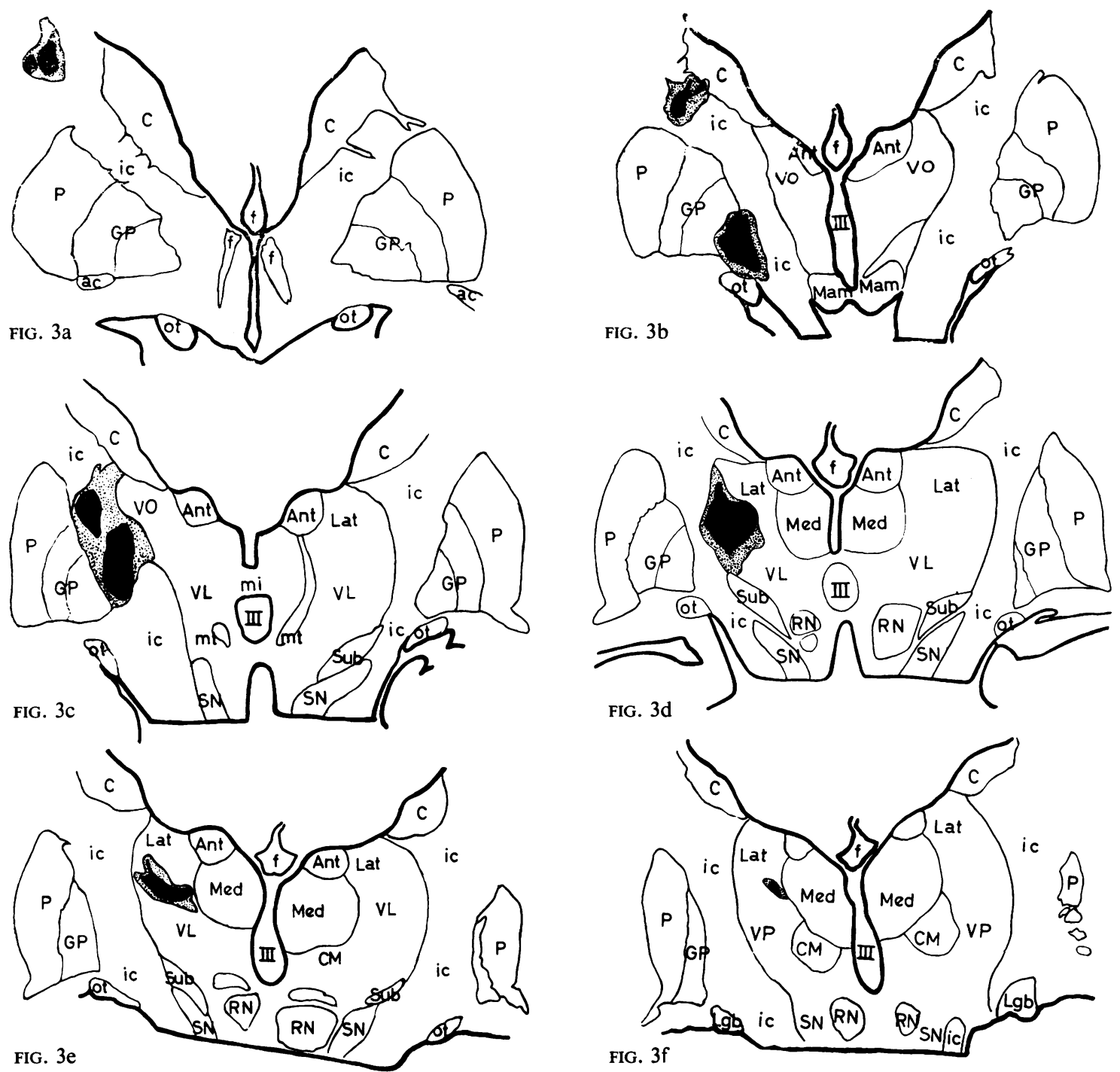

FIG. 3a to f. Case 1: Drawings from camera lucida tracings of histological preparations to show the extent of the surgical lesion. The first diagram represents a level approximately $4 \mathrm{~mm}$. behind the posterior margin of the anterior commissure in the midline; diagrams b to f represent levels posterior to this at intervals of $4 \mathrm{~mm}$. There are some minor distortions due to technical faults.

Solid black shading indicates total destruction of nervous tissue and replacement by granulation tissue and débris; the stippled areas show loss of nerve cells and fibres, demyelination, and astrocytic gliosis.

Diagram a shows the track of the cannula, surrounded by inflammatory tissue; just lateral to this, there is a second track, without inflammatory changes, believed to be due to the preliminary needling. It is not seen in subsequent sections. In diagrams $\mathrm{b}$ and $\mathrm{c}$ there appear to be two lesions. The upper one is the cannula track: the lower one is the forward extension of the main lesion, which is seen in diagrams $\mathrm{d}$ to $\mathrm{f}$.

Ant Anterior nucleus of thalamus

C Caudate nucleus

CM Centromedian nucleus of thalamus

GP Globus pallidus

Lat Lateral mass of thalamus

Lgb Lateral geniculate body

Mam Mammillary body

Med Dorsomedial nucleus of thalamus

P Putamen

RN Red nucleus
Sub Subthalamic nucleus

SN Substantia nigra

ac anterior commissure

f fornix

ic internal capsule

mi massa intermedia

$\mathrm{mt}$ mammillothalamic tract

ot optic tract

III Third ventricle.

VL, VO, VP: lateral, oral, and posterior divisions of ventral nucleus of thalamus 


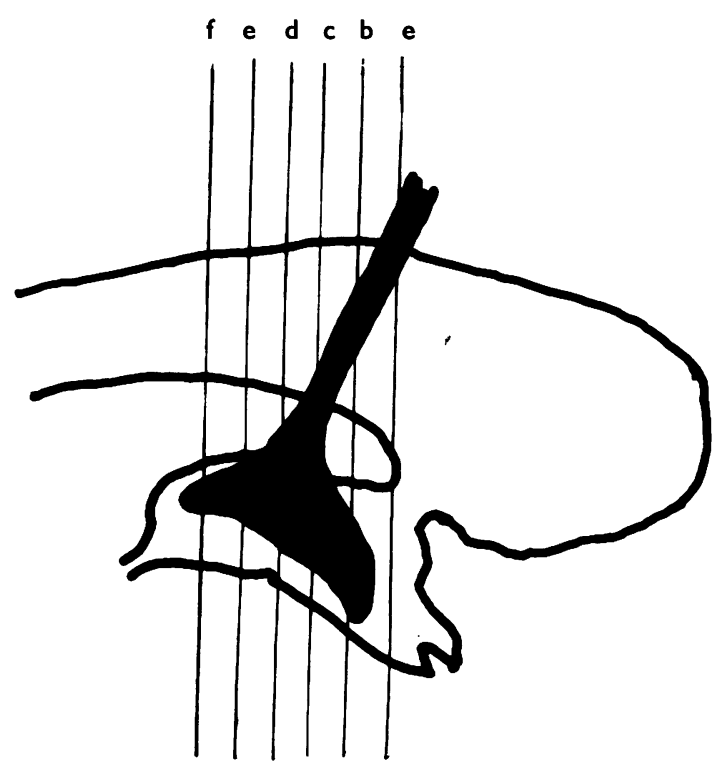

FIG. 3g. Case 1: A reconstruction of the lesion in lateral projection, superimposed on a tracing of the lateral and third ventricles. The vertical lines indicate the planes of diagrams 3 a to $3 \mathrm{f}$.

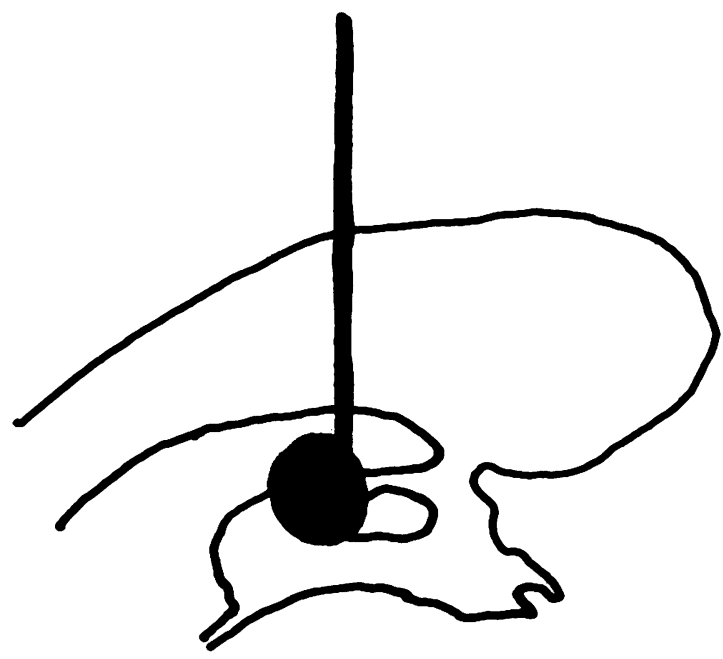

FIG. 3h. Tracing of lateral radiographs taken just after the balloon was inflated, for comparison with Fig. $3 \mathrm{~g}$.

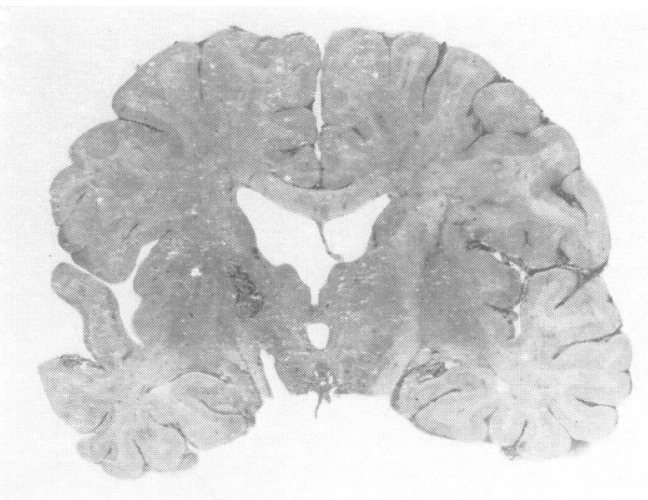

FIG. 4. Case 1: Photograph of coronal slice at the centre of the lesion (compare Fig. 3d).

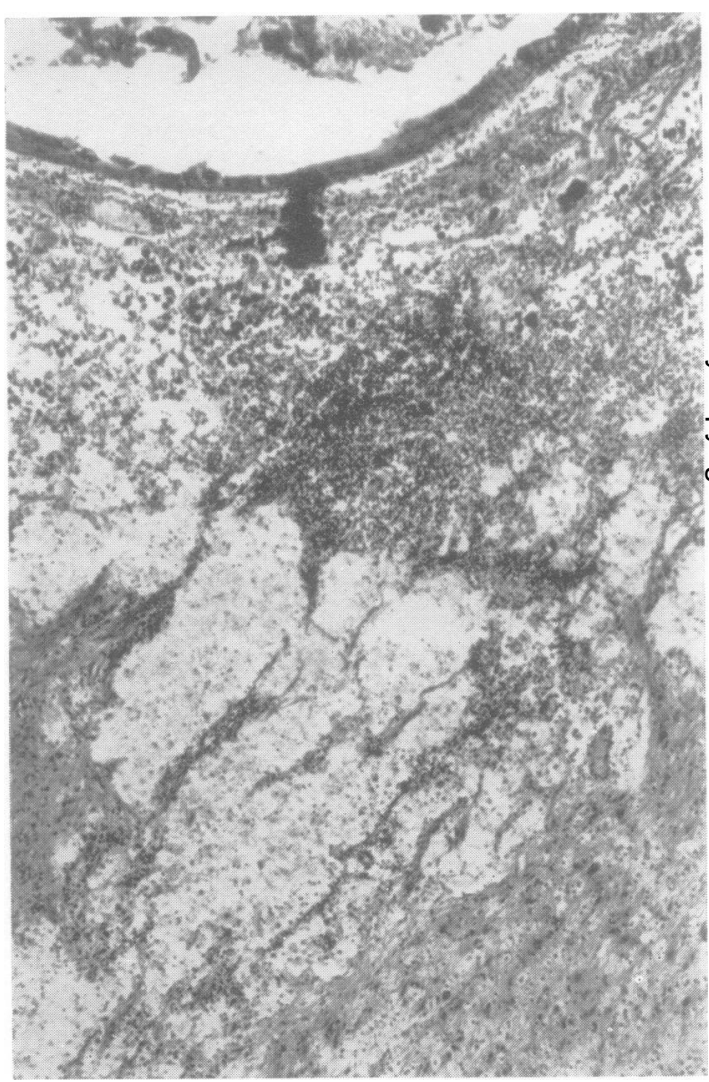

FIG. 5. Case 1: The various changes around the lesion. At the top is a darkly-stained fibrous 'capsule' surrounding a core of necrotic débris, and below it granulation tissue containing dark masses of Myodil; left and centre, strands of connective tissue enclose collections of lipid phagocytes. At bottom right is gliotic brain tissue. Haematoxylin and van Gieson, $\times 56$. 
taining numerous phagocytes laden with lipid and iron pigment, and an outermost zone (stippled in the diagrams) up to $3 \mathrm{~mm}$. wide, showing astrocytic proliferation, with partial loss of nerve cells and demyelination (Fig. 5). The track of the cannula showed similar changes to those in and around the main lesion, indicating that there had been a reflux of the injected material. Alongside this (Fig. 3a), and extending no further than the genu, was a simple needle track, without inflammatory changes, corresponding to the initial needling carried out before the Cooper cannula was placed in position.

It should be stressed that the measurements given above refer to the maximum extent of damage directly due to the lesion. In many parts, the margin of the lesion was very narrow; for instance, in some places apparently healthy thalamic neurones were seen within less than $0 \cdot 1 \mathrm{~mm}$. of the central cavity, and elsewhere there were well-preserved myelinated axons less than $0.1 \mathrm{~mm}$. away from the surrounding granulation tissue. It seems that the extent of diffusion of the alcohol had varied greatly in different directions, presumably as a result of tracking along tissue planes.

The extent of indirect damage to thalamic nuclei other than the lateral group was difficult to assess, except in the posteroventral group and centrum medianum, where there was clear evidence of loss of cells and of myelinated fibres, with gliosis. The medial and anterior nuclei of the thalamus, the subthalamic and the red nuclei, appeared to be spared, and there was no obvious degeneration in these areas.

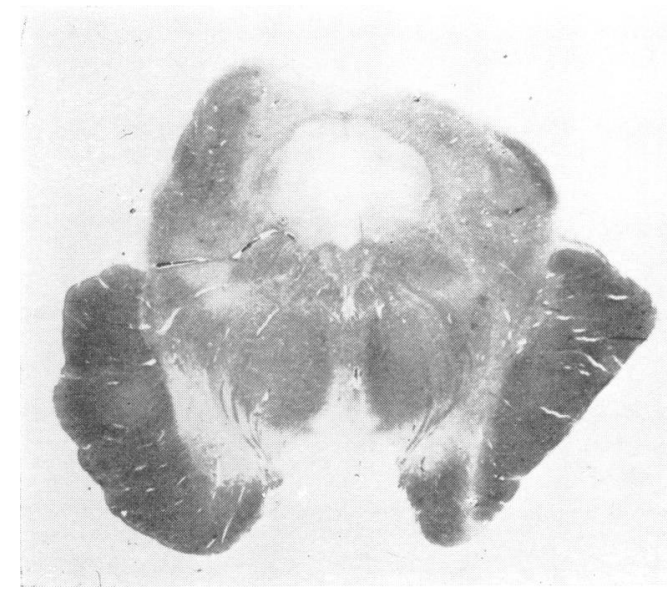

FIG. 6. Case 1: midbrain, showing band of Wallerian degeneration in the left crus (right side of picture).

Myelin stain, $\times 2$.
Thus the brunt of the damage was sustained by the lateral and ventrolateral nuclei of the thalamus, and a portion of the internal capsule just behind the genu. The resulting degeneration in the left crus is shown in Fig. 6. There is a band of Wallerian degeneration in the medial third of the crus, where the frontopontine fibres are said to run. The middle third, which is said to include the cortico-spinal tract, is virtually intact. In keeping with this, there is no detectable degeneration in the medullary pyramid.

CASE 2 (R.I. No. 274546) A right-handed 53-year-old engineer had developed tremor and rigidity of the right arm and leg over a period of five years. He could no longer fasten buttons, strike matches, or manipulate a micrometer, and had been forced to give up his job. His stance and gait were Parkinsonian. Otherwise he was well preserved, and emotionally normal and cheerful. On formal testing, he was above average in intelligence, and his memory and speech were intact. There was nothing to suggest an encephalitic origin of the disease.

A left thalamolysis was undertaken. The placing of the Cooper cannula was satisfactory, and radiographically identical with that in Case 1 . The tremor and ridigity of the right limbs were virtually abolished by the mere introduction of the cannula. When the balloon was inflated with $0.5 \mathrm{ml}$. Myodil it was discovered that some Myodil was escaping along the cannula track (Figs. 7 and 8 ). As a satisfactory result had already been achieved, nothing further was done at this stage. The patient appeared perfectly conscious and rational at the end of the operation, but six hours later he became confused, disorientated, euphoric, restless, and doubly incontinent. He gave a circumstantial account of a football match from which he had just returned, in which his team had won 4-0. This confabulation was repeated on several occasions, but it was not discovered whether the patient was remembering or imagining the incident.

During the next week he remained alert, but disorientated, deluded, euphoric, restless, and incontinent. He thought that the year was 1956, not 1959, and stated fairly consistently that he was in Coventry, his native town. His answers to questions tended to be either facetious or evasive; for instance, when asked why he was in hospital, he replied: 'To discuss the situation', but could not enlarge on this. He was clearly dysphasic, his memory for the immediate past was grossly deficient, and he showed no insight into his condition. He had a slight right facial weakness and bilateral extensor plantar responses, but no weakness of the limbs. Tremor and rigidity had disappeared on the right, and the fingers of the right hand could perform fine manipulations. During this period serial injections of Etopalin were given, totalling $1.25 \mathrm{ml}$, without obvious immediate effects.

The mental state improved steadily during the next month. He became aware of his position in time and space, was continent, and had sufficient insight to complain of some difficulty in thinking and in finding the right words. His memory had improved but was still defective. He remembered the operation itself, but little or nothing of the subsequent three weeks. Psychometric 


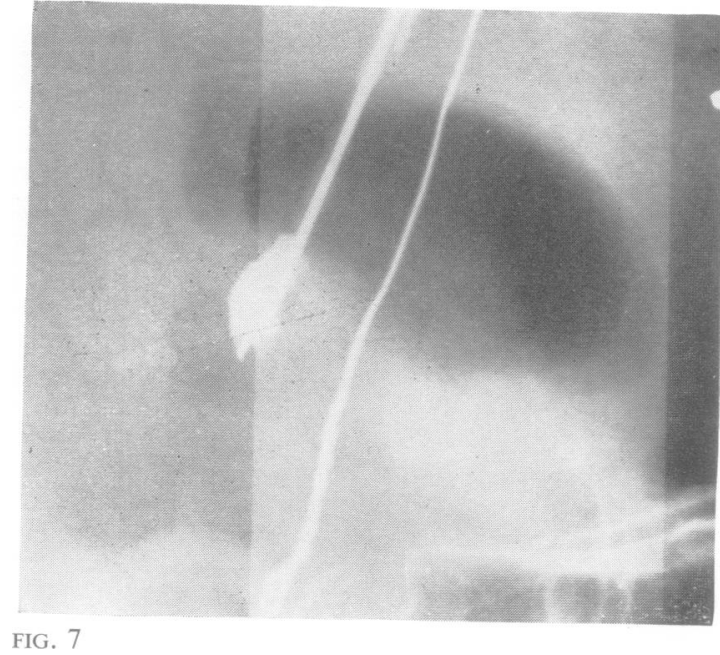

FIGS. 7 and 8. Case 2: lateral and antero-posterior radiographs, showing escape of Myodil after inflation of the balloon.

testing one month after operation showed a reduction of the verbal 1.Q. (Wechsler-Bellevue form II) from a preoperative level of 114 to 100 . The patient was careless, where he had previously been painstaking; he gave irrelevant answers to questions; and complained spontaneously of difficulty in thinking and in talking. At three, and again at five, months, his scores approached the pre-operative ones, and short-term memory was thought to be unimpaired; on the other hand, there was an ill-defined personality change, and evidence of emotional instability.

He was judged fit to return to work, but did not do so until 11 months after the operation. The latest reports, 18 months after operation, are not encouraging. At work, the patient appears unable to concentrate, or to think logically about current technical problems; in fact, it is difficult to find useful work for which he is mentally adequate. Formal testing confirms this deterioration; the verbal I.Q. was 98 at 18 months compared with 109 at five months and 114 before operation. The reason for this late decline, after an apparently good recovery, is still obscure.

\section{DISCUSSION}

These two cases have much in common. Both patients were middle-aged men, with severe Parkinsonian tremor affecting mainly the right side. Both underwent the same operative procedure on the left thalamus. In both, there was a gratifying alleviation of the Parkinsonian symptoms on the opposite side, without significant motor or sensory side-effects: and both suffered a very severe mental disturbance, followed by a slow recovery. The mental changes

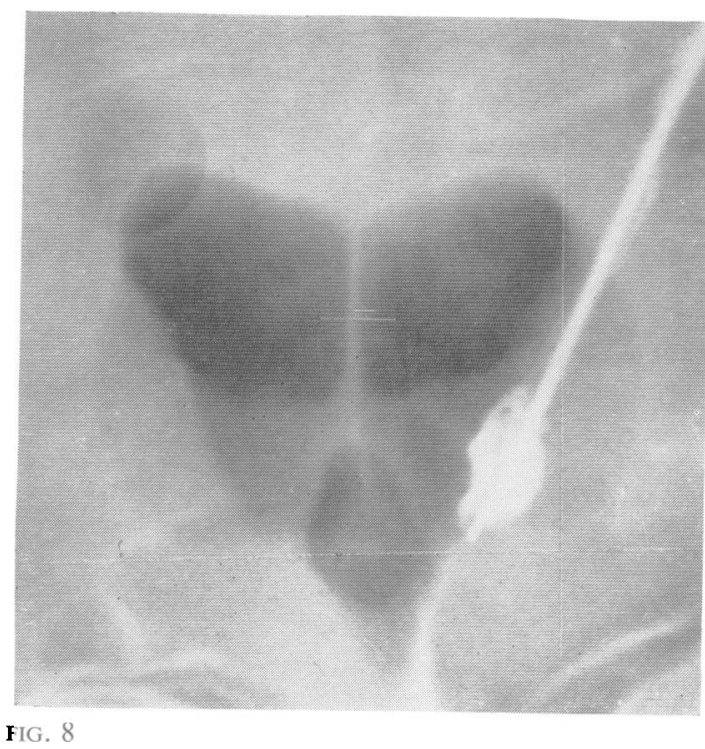

common to the two cases included confusion and disorientation, loss of recent memory, confabulation, euphoria, restlessness, and incontinence. Both also developed dysphasia. Thus two questions have to be considered: first, whether the mental disturbances can be attributed to damage in any particular anatomical site; second, to what extent the technique of the operation was responsible for these complications.

From published reports it appears that a florid and prolonged mental disorder, such as our cases exhibited, is a rare complication of surgery in this region on patients without signs of previous mental impairment. Cooper (1959) noted mental confusion in $8 \%$ of 850 operations on the thalamus and globus pallidus (he does not state the site of the lesion in these 68 patients). He claims (1961) that this complication was transient in every case, and was commoner after operation on the dominant side. Gillingham, Watson, Donaldson, and Naughton (1960) report six patients, out of a series of 60 , treated by electrocoagulative lesions, who showed mental changes as a result of operation. Two of these, who had bilateral pallidal lesions, became inert or stuporose. Two, with lesions believed to be in the left internal capsule, showed a transient dysphasia. The remaining two, with well-placed single lesions in the thalamus of the dominant hemisphere, produced florid psychotic reactions. The first of these two cases (their Case 51) was already confused before operation. The psychotic reaction (details are not given) developed as soon as the electrode entered the thalamus, and lasted for three weeks, after which 
the patient reverted to his preoperative state of fluctuating confusion. In the second (their Case 34) there was also pre-existing mental confusion. After operation a severe confusional state ensued which lasted about four weeks. Finally, Krayenbühl, Wyss, and Yasargll (1961) report 'psychomotor disturbances and altered consciousness' in eight out of 23 cases of bilateral electro-coagulative lesions in the posterior oral ventral nucleus. In two of these, following the second operation, which was on the right side, the effect was severe and long-lasting. Psychomotor disturbances also occurred in 17 out of 28 cases with lesions in the thalamus of one side and the pallidum of the other. Six of these were severe. Of these 51 cases, six showed some sort of mental disturbance after the first operation, which was carried out on the left thalamus in four instances, the left pallidum in one instance, and the right pallidum in one instance. No such complications have been reported in other long series, such as those of Hankinson (1960, 61 cases) and Bennett (1960b, over 100 cases). The former employs a thermocoagulative method, producing lesions 5 to $7 \mathrm{~mm}$. in diameter, and, like Gillingham et al., prefers a posterior approach from a parietal burr hole. The latter, using a highly accurate stereotactic technique (Bennett, 1960a) and making a small (0.1 to $0.5 \mathrm{ml}$.) injection of alcohol into the ventrolateral thalamic nucleus, has noted no mental ill-effects other than a transient euphoria. All these authors agree in believing that mental disturbances are not to be expected, even after operation on the dominant side, unless the lesion is ill-placed or too extensive or there is pre-existing mental impairment. We see no reason to disagree with this opinion.

Of our two patients, the first showed a depressive tendency before operation, but no impairment of memory or intelligence. The second appeared intellectually and emotionally intact. The placing of the centre of the lesion has been shown to be correct in Case 1, and is believed to have been so in Case 2; the effect on tremor and rigidity in both cases was satisfactory. On the other hand, it has been seen that the lesion in Case 1 had spread far beyond the target area, and it is very probable that the same had occurred in Case 2. Thus we are strongly inclined to attribute these patients' mental disorders to unintended damage to structures more or less remote from the target area.

It would be of great practical value to discover precisely what anatomical structures are involved in this syndrome. At present, the material evidence on this point is scanty, though it is probable that much could be learnt from the comparison of anatomical lesions in a number of similar cases. Meanwhile, we wish to draw attention to the two rostral extensions, seen in diagrams $3 b$ and $c$, of the lesion in Case 1. The more ventral of these, which involves the globus pallidus and the ansa lenticularis, lies within the territory of the anterior choroidal artery. It is interesting that Cooper (1961) mentions confusion and disturbances of memory as complications of the deliberate occlusion of this vessel.

An important question, which cannot at present be answered, is whether the hemisphere which is 'dominant' for speech is also in some sense 'dominant' for rational thought. Alford (1933) maintains that basal lesions in the left hemisphere carry more risk of mental disturbance than similar lesions on the right; and this suspicion seems to be shared by several of the authors quoted above. On the other hand, Krayenbühl et al. (1961) cite a number of cases in which operation on the left side has been uncomplicated, but subsequent operation on the right side has resulted in severe mental disturbance. Our own experience is limited, and we cannot contribute much to this discussion. We have seen mental disturbances following right-sided thalamic operations, but none with the distinctive features of the two cases presented here.

Turning to the practical issues raised by these two cases, we wish to stress two points; first, that an operation which carries an appreciable risk of provoking a major psychic disorder should be either discarded or modified so as to render the risk negligible. The second is that the lesions produced by the balloon-and-cannula technique, however accurately they may be placed, are too diffuse and incalculable in their spread to be safely inflicted, at any rate in the thalamus of the dominant hemisphere.

There seem to be two main hazards in this technique, even after the problems of accurate placement have been solved. The first is the inflation of the balloon. This necessarily involves disruption of nervous tissue and tearing of fibre tracts and blood vessels. The tissue is not a homogeneous pulp; it has planes of cleavage, and is held together mainly by blood vessels, the pattern of which is variable. Thus the pattern of tearing and disruption caused by the balloon is largely unpredictable. So, also, is the pattern of secondary damage to nervous tissue by infarction or haemorrhage caused by the tearing of vessels.

The second hazard lies in lack of control over the diffusion of chemical substances introduced into the cavity. This is well recognized (see, for example, Carpenter and Whittier, 1952; Gildenberg, 1957; Housepian and Guzman-Lopez, 1957), and is to some extent overcome by the preliminary formation of a cavity by the balloon and by using a viscous injection mass. When a lesion is found to be unduly 
large, it is difficult to decide which of these two hazards has been responsible, but we have reason to suspect that both can play an important role. In the first of our two cases, mental derangement occurred instantaneously after the inflation of the balloon, and can only be attributed to immediate trauma. In the second, the disturbance occurred after about six hours. In this case, we are inclined to suspect a vascular accident secondary to the trauma. As an example of the effect of chemical spread, we can cite a case where an electrolytic lesion was made in the left thalamus, with immediate abolition of a severe right-sided tremor, and with no mental or other sideeffects. Four days later, in order to ensure a permanent lesion, $\mathbf{0 . 2} \mathrm{ml}$. of Etopalin was injected at the same point. After this the patient became drowsy, confused, and dysphasic, and made a slow recovery over the next few weeks.

In making these criticisms of the balloon-andcannula technique, we are well aware that in general, and in competent hands, it works well. We believe, however, that the lesions it produces are dangerously large. Two cases which recently came to necropsy at the Radcliffe Infirmary several months after operations on the right thalamus, without major complications, showed lesions even larger and more irregular than the one we have described above. We are also prepared to face the charge that it is not the technique, but our handling of it, which is at fault. We shall readily admit the justice of this charge when we have seen a careful anatomical study of a series of such cases, showing small, well-defined lesions.

\section{SUMMARY}

Two cases are reported, in which a left thalamolysis by balloon-and-cannula technique resulted in severe and prolonged mental disturbance, with confabulation, confusion and amnesia.

The lesion in one of these cases has been examined histologically and its extent determined.

Attention is drawn to the lack of control over the size and spread of lesions produced by this technique. It is suggested that the method is unsuitable for use in the dominant hemisphere.

We are indebted to Mr. Joe Pennybacker, in whose department the treatment of these cases was carried out; to Mrs. Susan M. Gillies, clinical psychologist at the Warneford Hospital, Oxford; and to Dr. T. P. S. Powell, of the Department of Human Anatomy, Oxford, for his valuable advice on the anatomical features of Case 1.

\section{REFERENCES}

Alford, L. B. (1933). Amer. J. Psychiat., 12, 789.

Bennett, A. M. H. (1960a). Brit. J. Radiol., 33, 343.

(1960b). Personal communication.

Carpenter, M. B., and Whittier, J. R. (1952). J. comp. Neurol., 97, 73.

Cooper, I. S. (1959). Proc. roy. Soc. Med., 52, 47.

- (1961). Parkinsonism. Thomas, Springfield, Illinois.

Gildenberg, P. L. (1957). Confin. neurol. (Basel), 17, 299.

Gillingham, F. J., Watson, W. S., Donaldson, A. A., and Naughton, J. A. L. (1960). Brit. med. J., 2, 1395.

Hankinson, J. (1960). Postgrad. med. J., 36, 242.

Housepian, E. M., and Guzman-Lopez, M. (1957). Neurology, 7 763.

Krayenbühl. H., Wyss, O. A. M., and Yasargll, M. G. (1961). J Neurosurg., 18, 429. 